\title{
Land management and land-cover change have impacts of similar magnitude on surface temperature
}

\author{
Sebastiaan Luyssaert et al. ${ }^{\dagger}$
}

\begin{abstract}
Anthropogenic changes to land cover (LCC) remain common, but continuing land scarcity promotes the widespread intensification of land management changes (LMC) to better satisfy societal demand for food, fibre, fuel and shelter ${ }^{1}$. The biophysical effects of LCC on surface climate are largely understood ${ }^{2-5}$, particularly for the boreal ${ }^{6}$ and tropical zones ${ }^{7}$, but fewer studies have investigated the biophysical consequences of LMC; that is, anthropogenic modification without a change in land cover type. Harmonized analysis of ground measurements and remote sensing observations of both LCC and LMC revealed that, in the temperate zone, potential surface cooling from increased albedo is typically offset by warming from decreased sensible heat fluxes, with the net effect being a warming of the surface. Temperature changes from LMC and LCC were of the same magnitude, and averaged $2 K$ at the vegetation surface and were estimated at $1.7 \mathrm{~K}$ in the planetary boundary layer. Given the spatial extent of land management (42-58\% of the land surface) this calls for increasing the efforts to integrate land management in Earth System Science to better take into account the human impact on the climate ${ }^{8}$.
\end{abstract}

Human activities have directly affected around $100 \mathrm{M} \mathrm{km}^{2}$ of the ice-free land surface leaving, as of today, less than $30 \%$ of the land surface largely untouched (Supplementary Table 1). Of this, between 23 and $38 \mathrm{M} \mathrm{km}^{2}$ (18-29\% of the land surface) has been deliberately converted, mainly by deforestation, for agriculture, infrastructure and urban use. These land cover changes (LCCs) have driven changes in regional and global climate through changes in biogeochemical processes (for example, $\mathrm{C}$ and $\mathrm{N}$ cycling) and biophysical processes (for example, surface albedo, surface roughness, and evapotranspiration $)^{1,9}$. A more complete assessment of human contributions to climate change will require the climatic influence of land-surface conditions to be factored into climatechange mitigation strategies ${ }^{5}$.

To date, many studies have investigated the climate effects of changes in land cover; but, with the exception of irrigation effects $^{10,11}$, have rarely looked into the climate impacts of land management changes (LMC) that occur within the same land cover type and do not result in a LCC (for precise definitions see Supplementary Section 1). However, $55-75 \mathrm{M} \mathrm{km}^{2}$ (42-58\% of the land surface) have not experienced LCC but are managed to satisfy human demands (Supplementary Table 1). Within land cover types, LMC varies in fertilization and pesticide use, harvest rate, and cropping practices, to mention only a few. For example, $19 \mathrm{M} \mathrm{km}^{2}$ of forest, representing $15 \%$ of global ice-free land, is subjected to diverse management strategies for wood production and other services that result in changes in albedo, surface roughness, $\mathrm{C}$ sequestration, other trace gas fluxes, and sensible and latent heat flux, without changing land cover type $\mathrm{e}^{12,13}$.
Owing to the predicted increases in global population and affluence as well as the increasing importance of bioenergy ${ }^{14}$, demand for land-based food and fibre will surge during the coming decades. Expansion of active management into relatively untouched regions may satisfy part of the growing demand. However, owing to the prohibitively high carbon costs of converting pristine forests to cultivated land ${ }^{15}$, and the looming scarcity of unused but productive $\operatorname{land}^{16}$, intensification will play a decisive role in forging strategies for global sustainability ${ }^{17,18}$ and enhance the role that LMC plays in human economies and, importantly, in the climate system.

We tested the hypothesis that LCC and LMC have biophysical effects of similar magnitude to surface and atmospheric climate per unit land area. To address the hypothesis, we selected from the FLUXNET database 22 temperate and two boreal Eurasian and American multi-year eddy covariance research sites with highquality data (Supplementary Fig. 1 and Tables 2 and 3). All sites were paired and 33 out of 351 possible pairs that represented either LCC or LMC were selected for study based on similarity in incoming radiation and energy budget closure (Supplementary Section 2.2.4). Nine of these pairs resulted from a formal paired ecosystem experimental set-up.

We found that LCC and LMC had similar impacts on site-level mean annual radiometric surface temperature (Fig. 1a,b). Mean and upper limit temperature responses to LCC and LMC were similar (Fig. $1 \mathrm{~b}$ ) and around $2 \mathrm{~K}$ at the site-level, with a maximum of $6 \mathrm{~K}$. Because LCC was used as a benchmark for LMC and our findings for LCC are in agreement with previous observations regarding LCC in the tropics ${ }^{3,7}$, Mediterranean $^{19}$ and the boreal zone ${ }^{6}$ our study lends support to the hypothesis that LMC other than irrigation ${ }^{10,11}$ also has substantial biophysical impacts on the land surface.

No single accepted approach exists to quantify intensities of LCC and LMC. Although intensity is often thought of in terms of input-for example, fertilizer, irrigation or fossil fuels-it may also be expressed in terms of its output-for example, change in yield or, as applied in this study, biophysical metrics such as the change in surface albedo. Following this definition, more intense LCC or LMC are those land uses that result in larger albedo changes, which were observed to be significantly and positively correlated with larger changes in radiometric surface temperature (Fig. 2a; Pearson correlation, $p<0.05)$.

The site-level analysis was extended by eight time series of MODIS satellite observations (MOD11A2 from 2009 to 2011) of $2,500 \mathrm{~km}^{2}$ areas intersected by administrative borders with similar climate but different land cover and land management types (Supplementary Table 4). Remote sensing products do not distinguish managed from unmanaged vegetation. Test-case selection thus requires ground information; therefore, only a limited number of areas were selected for study. The use of remote sensing data confirmed 
a

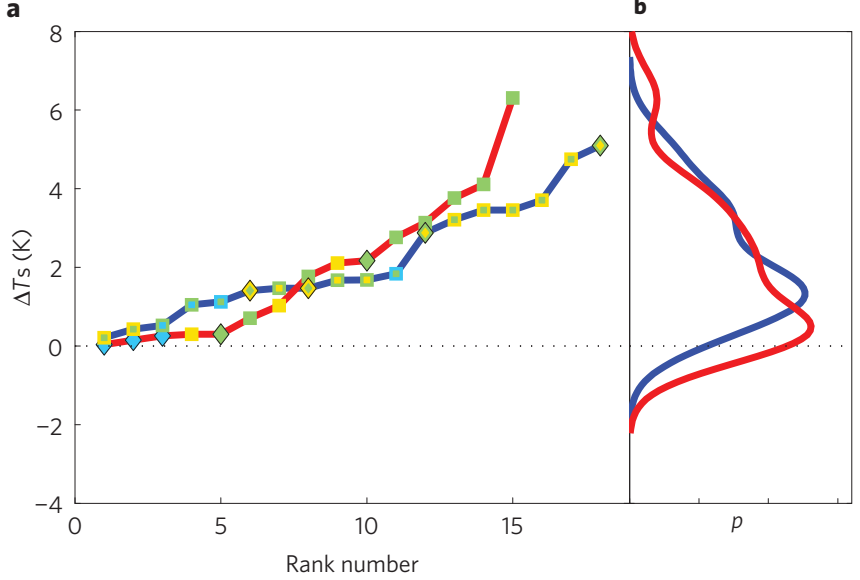

Figure 1 | Effects of land cover change and land management on surface temperature. a, Change in radiometric surface temperature $\left(T_{\mathrm{S}}\right.$ in $\left.\mathrm{K}\right)$ for paired eddy covariance measurement sites (Supplementary Table 3) due to biophysical effects of land cover change (blue) or land management (red), ranked by magnitude. The edge of the marker shows the initial land cover, whereas the interior shows the final land cover, with green for forest, yellow for grassland and blue for cropland. Formal experimental site pairs are marked with a diamond and all other pairs are marked with a square. $\mathbf{b}$, Probability density estimates for the surface temperature effects of land cover change (blue) and land management change (red). Radiometric temperature was assumed to have a $0.75 \mathrm{~K}$ uncertainty, which explains the negative values for $T_{\mathrm{s}}$

the relationship between albedo and temperature and established its validity at larger spatial scales (Fig. 2b; Pearson correlation, $p<0.01)$. Despite its robustness across spatial scales and ecosystems, the observation that an increase in albedo is related to an increase in surface temperature may seem paradoxical if less energy is available for surface heating following an increase in albedo.

A literature search (Supplementary Table 5) showed that from more than 30 studies reporting biophysical effects of LMC all, except one $^{20}$, did not consider all of the major components of the energy budget. We, therefore, extended an energy balance decomposition approach ${ }^{12,21}$ and analysed the change in surface temperature due to changes in albedo, ground heat, and sensible and latent heat while accounting for the differences in incoming radiation and imbalances in the energy budget. Despite the sites being well-watered, their Bowen ratio indicates that the sensible heat flux is the dominant mechanism for terrestrial surface cooling (for site-level data on the Budyko index and Bowen ratio see Supplementary Table 2). Across all paired observations, the potential for cooling the surface due to an increase in albedo (Fig. 2a) was outweighed by the potential for warming due to decreased fluxes of sensible heat (Fig. 3a; Pearson correlation, $p<0.01$ ) but not latent heat (Fig. $3 b ; p=0.88$ ). Lack of correlation between the imbalance term and the major components of the energy budget (Supplementary Fig. 3 and Section 2.2.1) strengthens our confidence that the observed relationships are not artefacts. For the sites under study, sensible heat and changes in sensible heat thus seem to be key drivers of the surface temperature and its changes following LCC or LMC.

Surface roughness information for the area encompassing the flux footprint was missing for half of the sites. Alternatively, a proxy for canopy structure, defined as the logarithm of vegetation height divided by leaf area index (LAI; ref. 22), was used. A previously reported relationship between canopy structure and albedo ${ }^{6}$ was present at the study sites (Supplementary Fig. 4a). Furthermore, larger and more structured canopies transfer more momentum from the planetary boundary layer (PBL) to the leaf surface than smaller canopies $^{3}$. A negative correlation, but no causation, between albedo and momentum flux is thus expected because of shared common drivers-namely, height, LAI, and crown dimensions. The observed decoupling between sensible (Supplementary Fig. $4 b, p<0.01$ ) and latent heat flux (Supplementary Fig. $4 c, p=0.16$ ) emphasizes the important role of stomatal conductance to surface-atmosphere transport ${ }^{6}$. Although the sites studied here are dominated by forest and grasslands, croplands did not seem to be outliers in any of our analyses.

Whereas the surface temperature response to LCC has long since been understood for boreal (that is, decreases in surface albedo and increases in surface temperature following afforestation, due to snow-masking ${ }^{23,24}$ ) and tropical ecosystems (that is, decreases in evapotranspiration following deforestation tend to outweigh increases in albedo on surface temperature ${ }^{25}$ ), our study reveals that changes in sensible heat flux outweigh changes in albedo and underlie surface temperature changes in the temperate zone following both LCC and LMC. To the best of our knowledge, our study is the first data analysis showing that the same mechanism
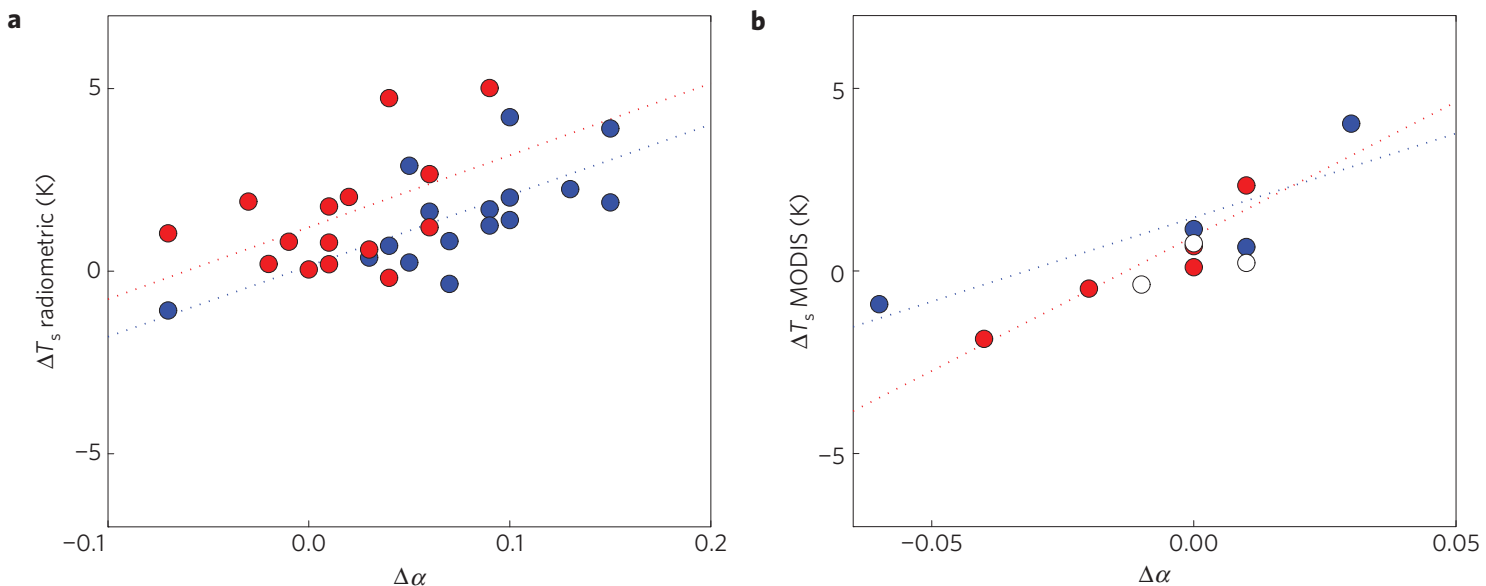

Figure $\mathbf{2}$ | The relationship between changes in albedo $(\Delta \alpha)$ and changes in surface temperature $\left(\Delta T_{\mathrm{s}}\right)$ following land cover conversions (blue) and land management change (red). a, The relationship between changes in albedo and radiometric surface temperature from paired ecosystems in the databases of eddy covariance research sites $(p<0.05)$. b, MODIS-derived surface temperature $\left(T_{s}\right)$ and albedo (mean of visible $300-700 \mathrm{~nm}$ and near infrared $700-1100 \mathrm{~nm}$ ) between both sides of an administrative border $(p<0.01)$. White dots show changes observed at homogeneous landscapes (Supplementary Table 4). 


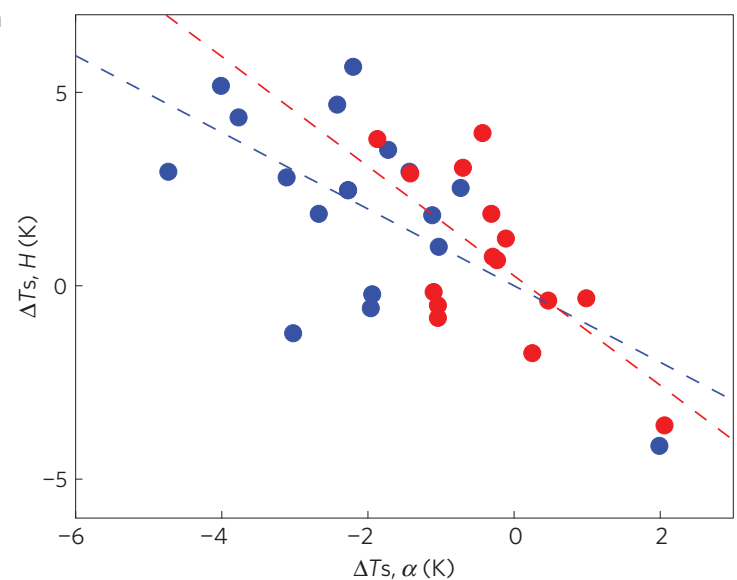

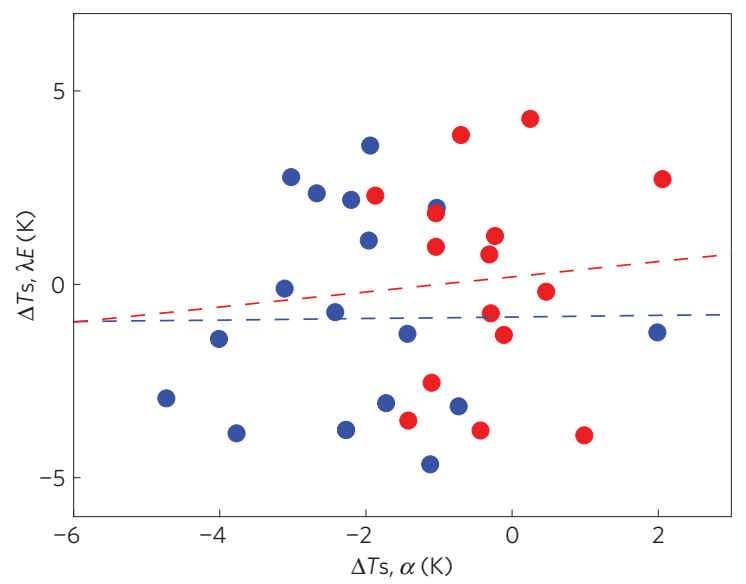

Figure 3 | Biophysical effects of land cover change (blue) or land management (red). a, Relationship between the change in radiometric surface temperature due to a change in albedo and the contribution of sensible heat flux $(H)$ to the change in $T_{s}(p<0.01)$. $\mathbf{b}$, Relationship between the change in radiometric surface temperature due to a change in albedo and the contribution of latent heat flux $(\lambda E)$ to the change in $T_{\mathrm{s}}(p=0.88)$.

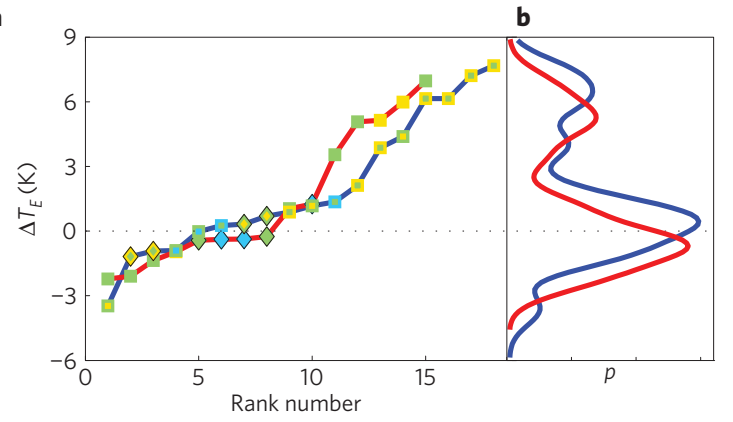

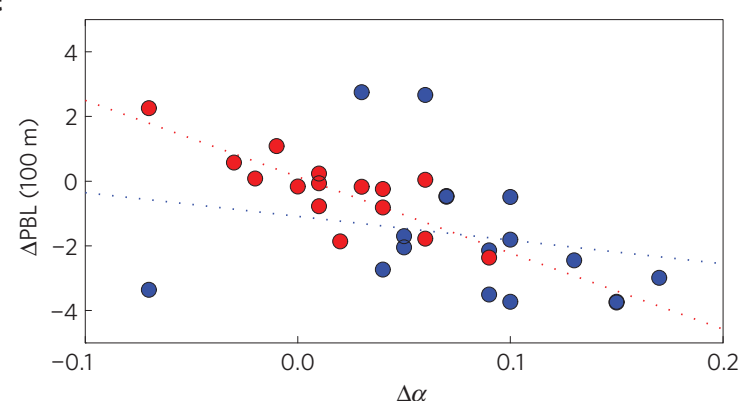

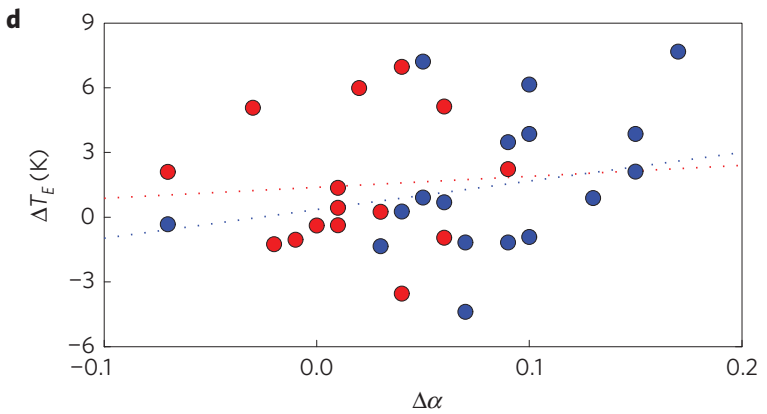

Figure 4 | Effects of land cover change and land management on the height and equivalent temperature of the planetary boundary layer. a, Change in equivalent temperature $\left(T_{E}\right)$ for paired eddy covariance measurement sites (Supplementary Table 3 ) due to the biophysical effects of changes in land cover (blue) or land management (red), ranked by magnitude. The edge of the marker shows the initial land cover whereas the interior shows the final land cover, with green for forest, yellow for grassland and blue for cropland. Formal experimental site pairs are marked with a diamond and all other pairs are marked with a square. $\mathbf{b}$, Probability density estimates for the equivalent temperature ( $T_{E}$ ) effects of land cover change (blue) and land management (red). Equivalent temperature was assumed to have a $0.75 \mathrm{~K}$ uncertainty, which explains its negative values. $\mathbf{c}$, Relationship between the change in albedo and the estimated change in the height of the planetary boundary layer by applying a 1D boundary layer model $(p<0.01)$. $\mathbf{d}$, Relationship between the change in albedo and the estimated change in equivalent temperature of the planetary boundary layer by applying a 1D boundary layer model $(p=0.33)$.

controlling surface temperature changes following LCC may control surface temperature changes following LMC in the temperate zone, but improved observations of surface roughness at the site-level and additional controlled experiments are required to confirm our field observations.

Despite surface temperature being a meaningful measure for the temperature experienced by the vegetation cover and all living organisms within ${ }^{26}$, it fails to capture the effects of LCC and LMC on the climate system. Quantifying the full climate effects of LMC and LCC is out of reach for site-level and remote sensing observations and requires coupled surface-atmosphere models to account for boundary layer dynamics, planetary albedo from clouds and aerosols, precipitation, and radiative forcing from changes in atmospheric composition through $\mathrm{C}$ and $\mathrm{N}$ cycling.

However, as a first-order estimate of the climate effect, a 1D-PBL model can be used to calculate the equivalent temperature of the PBL (refs 19,27,28). This approach accounts for the growth of the boundary layer, the differential effect of sensible and latent heat fluxes and the entrainment of colder air from above the PBL, but assumes convective clear sky conditions. Both LCC and LMC were found to increase the equivalent temperature of the $\mathrm{PBL}$ by on average $1.7 \mathrm{~K}$ (Fig. 4a,b). Although the mean temperature changes suggests a smaller effect on the PBL (Fig. 4a,b) compared to the vegetation surface (Fig. 1a,b), the feedback of the PBL 


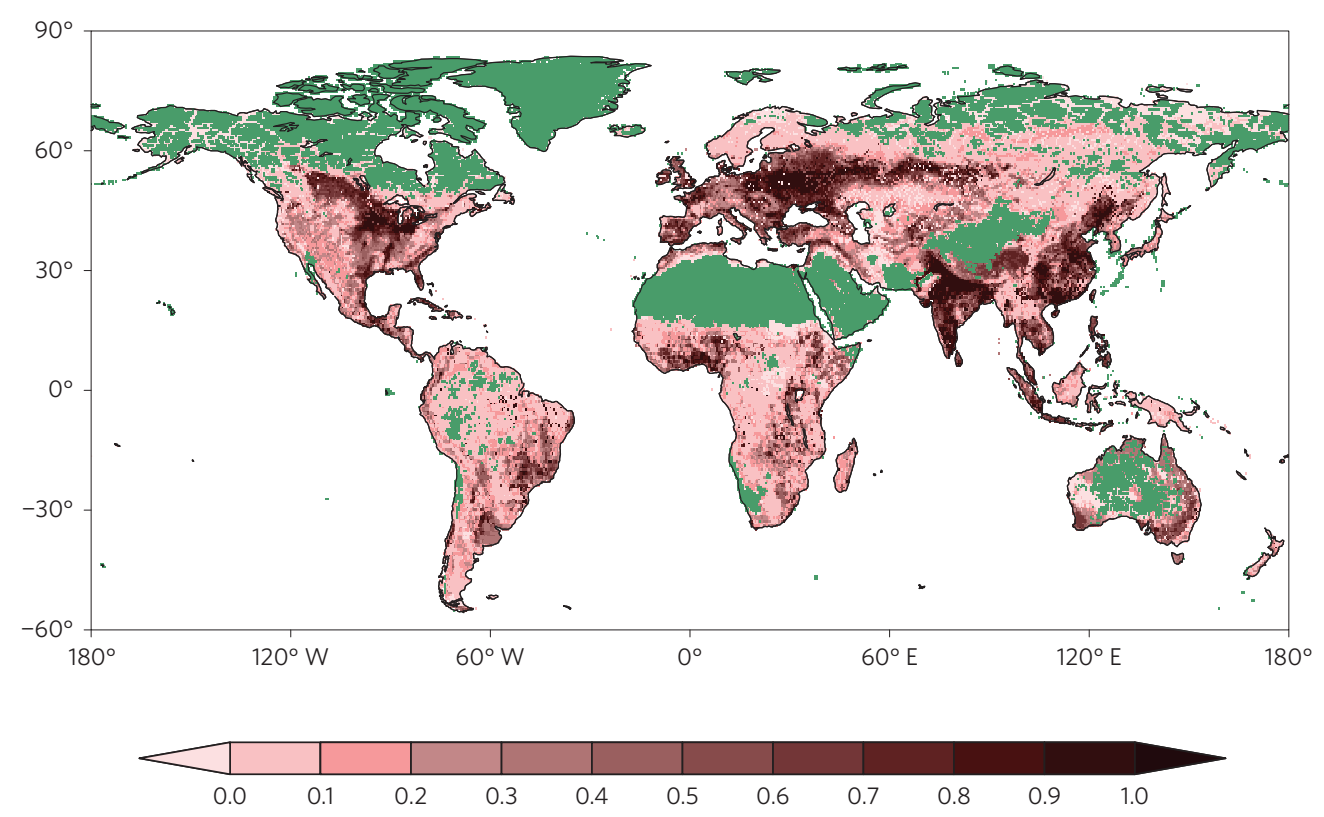

Figure 5 | Spatial extent of land cover change, land management, wilderness and non-productive areas (Supplementary Section 2.3). Wilderness and non-productive areas are shown in green and represent land largely unaltered by humans. The remaining land is used for producing food, fibre and fuels, and for hosting infrastructure. The colour scale represents the fraction of each grid cell for which the original plant cover was converted. Dark colours indicate regions where most of the original plant cover was converted; these regions are the subject of typical land cover change studies. The light colours show areas for which land cover change is low, but which are nevertheless under anthropogenic land management.

model increases the temperature range, both positive and negative. Across site pairs, increases in albedo were found to correlate with decreases in sensible heat flux (Fig. 3a) and thus a decrease in PBL height (Fig. 4b; Pearson correlation, $p<0.01$ ). However, the relationship between land use intensity (based on the change in albedo) and change in equivalent temperature in the PBL did not hold (Fig. $4 c, p=0.33$ ). Larger ranges and loss of correlation illustrate the complexity of the effects of land use change on atmospheric temperature ${ }^{19}$, or the plausibility of the current PBL model, which does not capture any cloud or advective processes ${ }^{28}$.

Our results demonstrate, however, that the human influence on climate will not be represented adequately over vast areas of the land surface when LMC remains unaccounted for in models (Fig. 5). Similar to recent reconstructions of LCC that enabled historical and contemporary climate effects of LCC to be modelled ${ }^{29}$, accounting for LMC requires the development of spatially explicit global reconstructions describing the type and intensity of LMC. In conjunction with global reconstructions, the structure of global land surface models needs to be adjusted to incorporate key species and cultivars rather than relying on plant functional types; $3 \mathrm{D}$ or effective canopy structure rather than big leaf approximations; and possibly using within-canopy momentum models rather than applying coarse assumptions on the zero plane displacement height. Furthermore, the effects of fertilization, irrigation and grazing on canopy structure, and vegetation and background reflective properties should be accounted for.

The similarity between LCC and LMC sheds new light on the attribution of responsibilities in climate change. Historical LCCs such as in Europe and the USA are penalized less in political negotiations than recent cover changes in Latin America and Southeast Asia. The rationale is given by physical laws, which result in earlier emissions being largely transferred from the atmosphere to the ocean and land carbon pools ${ }^{30}$. Our results suggest that for a comprehensive assessment of human influences on climate, the effects of LMC have to be taken into account-that is, the climatic effects of recent intensification of LMC without cover change, such as the Green Revolution in Europe, US, China and India. The large biophysical effects of both LCC and LMC found in this study call for further extending the attribution of climate change from the prevailing greenhouse gas perspective to include biophysical effects $^{8}$. Better understanding the balance between biogeochemical and biophysical effects of LMC on radiative and non-radiative forcing would avoid promoting land management strategies with no guarantee of mitigating climate change.

Received 2 September 2013; accepted 11 March 2014; published online 13 April 2014

\section{References}

1. Foley, J. A. et al. Global consequences of land use. Science 309, 570-574 (2005).

2. Pielke, R. A. et al. Interactions between the atmosphere and terrestrial ecosystems: influence on weather and climate. Glob. Chang. Biol. 4, 461-475 (1998).

3. Bonan, G. B. Forests and climate change: forcings, feedbacks, and the climate benefits of forests. Science 320, 1444-1449 (2008).

4. Pielke, R. A. et al. Land use/land cover changes and climate: Modeling analysis and observational evidence. Wiley Interdiscip. Rev. Chang. 2, 828-850 (2011).

5. Mahmood, R. et al. Land cover changes and their biogeophysical effects on climate. Int. J. Climatol. 34, 929-953 (2013).

6. Beringer, J., Chapin, F. S., Thompson, C. C. \& McGuire, a. D. Surface energy exchanges along a tundra-forest transition and feedbacks to climate. Agric. For. Meteorol. 131, 143-161 (2005).

7. Da Rocha, H. R. et al. Patterns of water and heat flux across a biome gradient from tropical forest to savanna in Brazil. J. Geophys. Res. 114, G00B12 (2009).

8. McAlpine, C. et al. More than CO2: A broader paradigm for managing climate change and variability to avoid ecosystem collapse. Curr. Opin. Environ. Sustain. 2, 334-346 (2010).

9. Otterman, J. Anthropogenic impact on the albedo of the earth. Clim. Change 1, 137-155 (1977).

10. Boucher, O., Myhre, G. \& Myhre, A. Direct human influence of irrigation on atmospheric water vapour and climate. Clim. Dynam. 22, 597-603 (2004).

11. Bonfils, C. \& Lobell, D. Empirical evidence for a recent slowdown in irrigation-induced cooling. Proc. Natl Acad. Sci. USA 104, 13582-13587 (2007).

12. Juang, J.-Y. Y., Katul, G., Siqueira, M., Stoy, P. \& Novick, K. A. Separating the effects of albedo from eco-physiological changes on surface temperature along a successional chronosequence in the southeastern United States. Geophys. Res. Lett. 34, 1-5 (2007). 
13. Dore, S. et al. Carbon and water fluxes from ponderosa pine forests disturbed by wildfire and thinning. Ecol. Appl. 20, 663-83 (2010).

14. Tilman, D. et al. Beneficial biofuels - the food, energy, and environment trilemma. Science 325, 270-271 (2009).

15. Fargione, J., Hill, J., Tilman, D., Polasky, S. \& Hawthorne, P. Land clearing and the biofuel carbon debt. Science 319, 1235-8 (2008).

16. Lambin, E. F. \& Meyfroidt, P. Global land use change, economic globalization, and the looming land scarcity. Proc. Natl Acad. Sci. USA 108, 3465-3472 (2011).

17. Reid, W. V et al. Earth system science for global sustainability: Grand challenges. Sci. 330, 916-917 (2010).

18. Foley, J. A. et al. Solutions for a cultivated planet. Nature 478, 337-42 (2011).

19. Baldocchi, D. D. \& Ma, S. How will land use affect air temperature in the surface boundary layer? Lessons learned from a comparative study on the energy balance of an oak savanna and annual grassland in California, USA. Tellus B 65, 19994 (2013).

20. Rotenberg, E. \& Yakir, D. Distinct patterns of changes in surface energy budget associated with forestation in the semiarid region. Glob. Chang. Biol. 17, 1536-1548 (2011).

21. Stoy, P. C. et al. Separating the effects of climate and vegetation on evapotranspiration along a successional chronosequence in the southeastern US. Glob. Chang. Biol. 12, 2115-2135 (2006).

22. Cho, J. et al. Testing the hypothesis on the relationship between aerodynamic roughness length and albedo using vegetation structure parameters. Int. J. Biometeorol. 56, 411-418 (2012).

23. Bonan, G., Pollard, D. \& Thompson, S. Effects of boreal forest vegetation on global climate. Nature 359, 716-718 (1992).

24. Lee, X. et al. Observed increase in local cooling effect of deforestation at higher latitudes. Nature 479, 384-387 (2011).

25. Claussen, M., Brovkin, V. \& Ganopolski, A. Biogeophysical versus biogeochemical feedbacks of large-scale land cover change. Geophys 28, 1011-1014 (2001).

26. De Frenne, P. et al. Microclimate moderates plant responses to macroclimate warming. Proc. Natl Acad. Sci. USA 1-5 (2013).

27. Fall, S., Diffenbaugh, N. S., Niyogi, D., Pielke, R. a. \& Rochon, G. Temperature and equivalent temperature over the United States (1979-2005). Int. J. Climatol. 30, 2045-2054 (2010).

28. McNaughton, K. G. \& Spriggs, T. W. A mixed-layer model for regional evaporation. Boundary-Layer Meteorol. 34, 243-262 (1986).

29. Pitman, A. J. J. et al. Uncertainties in climate responses to past land cover change: First results from the LUCID intercomparison study. Geophys. Res. Lett. 36, 1-6 (2009).
30. Den Elzen, M. \& Schaeffer, M. Responsibility for past and future global warming: uncertainties in attributing anthropogenic climate change. Clim. Change 53, 29-73 (2002)

\section{Acknowledgements}

MODIS land surface temperature, black sky albedo, and the enhanced vegetation index were retrieved from the NASA Land Processes Distributed Active Archive Centre (LP DAAC, https://lpdaac.usgs.gov/). Site-level data were retrieved from the FLUXNET (http://daac.ornl.gov/), IMECC (http://gaia.agraria.unitus.it/) and AMERIFLUX (http://ameriflux.ornl.gov/) databases. Christophe Moisy prepared Supplementary Fig. 1. S.L., M.J., J.O., M.J.M., K.Naudts and J.R. were funded through ERC starting grant 242564 and received additional funding through FWO-Vlaanderen. M.J. received funding also through the Nordic Centre of Excellence, DEFROST, under the Nordic Top-Level Research Initiative and the Center for Permafrost, CENPERM DNRF number 100. T.K. and S.E. were funded through the Einstein Foundation and the European Commission (VOLANTE FP7-ENV-265104). K.H.E. acknowledges funding from ERC starting grant 263522 LUISE. E.C. and M.F. received funding from the European Commission, FEDER Interreg Iva, 723 POCTEFA08/34 and ADEME. M.W. acknowledges funding from the German Research Foundation (DFG) through the SPP1257 priority program, and the European Commission FP-7 226701 (CARBO-Extreme) and FP7-244122 (GHG-Europe), also for A.J.D. P.C.S. acknowledges funding from the US NSF EF \#1241881, the Marie Curie Incoming International Fellowship Programme, and the MT Institute on Ecosystems. The authors acknowledge the financial help of the European Commission through COST ES0805 for organizing the Potsdam workshop in support of this study, and the IMECC Integrated Infrastructure Initiative (I3) project under the 6th Framework Program (contract number 026188). This study contributes to the Global Land Project (http://www.globallandproject.org).

\section{Author contributions}

S.L., M.J., S.E., J.P., E.C., G.C., A.J.D., K.H.E., M.F., R.A.H., K.K., A.K., T. Kuemmerle, A.L., P.M., J.O., M.W. and P.C.S. designed the study. S.E., T. Kuemmerle. and J.O. analysed the remote sensing data. M.J., P.C.S., J.R. and S.L. analysed the site-level data. J.P., P.M. and K.H.E. analysed the land cover and land management data. E.C., A.J.D., A.D., M.F., B.G., T.G., A.K., T. Kolb, T.L., A.L., D.L., E.J.M., K.Novick, K.P., C.A.P., S.R., C.R., A.E.S., A.V. and P.C.S. provided site-level data. S.L., M.J., S.E., J.P., E.C., G.C., A.J.D., A.D., K.H.E., M.F., B.G., R.A.H., K.K., A.K., T. Kolb, T.Kuemmerle, A.L., M.J.M., P.M., E.J.M., K. Nauds, K. Novick, J.O., S.R., J.R., A.V., M.W. and P.C.S. contributed to discussing the results and writing the paper.

\section{Additional information}

Supplementary information is available in the online version of the paper. Reprints and permissions information is available online at www.nature.com/reprints. Correspondence and requests for materials should be addressed to S.L.

\section{Competing financial interests}

The authors declare no competing financial interests.

Sebastiaan Luyssaert ${ }^{1 \star}$, Mathilde Jammet ${ }^{2}$, Paul C. Stoy ${ }^{3}$, Stephan Estel ${ }^{4}$, Julia Pongratz ${ }^{5}$, Eric Ceschia ${ }^{6}$, Galina Churkina ${ }^{4}$, Axel Don ${ }^{7}$, KarlHeinz Erb ${ }^{8}$, Morgan Ferlicoq ${ }^{5}$, Bert Gielen ${ }^{9}$, Thomas Grünwald ${ }^{10}$, Richard A. Houghton ${ }^{11}$, Katja Klumpp ${ }^{12}$, Alexander Knohl13, Thomas Kolb ${ }^{14}$, Tobias Kuemmerle ${ }^{3,15}$, Tuomas Laurila ${ }^{16}$, Annalea Lohila ${ }^{16}$, Denis Loustau ${ }^{17}$, Matthew J. McGrath ${ }^{1}$, Patrick Meyfroidt ${ }^{18}$, Eddy J. Moors ${ }^{19}$, Kim Naudts', Kim Novick ${ }^{20}$, Juliane Otto ${ }^{1}$, Kim Pilegaard ${ }^{21}$, Casimiro A. Pio ${ }^{22}$, Serge Rambal ${ }^{23}$, Corinna Rebmann ${ }^{24}$, James Ryder ${ }^{1}$, Andrew E. Suyker ${ }^{25}$, Andrej Varlagin ${ }^{26}$, Martin Wattenbach ${ }^{27}$ and A. Johannes Dolman ${ }^{28}$

${ }^{1}$ Laboratoire des Sciences du Climat et I'Environnement (LSCE), 91190 Gif-sur-Yvette, France, ${ }^{2}$ University of Copenhagen, Department of Geosciences and Natural Resource Management, 1350 Copenhagen K, Denmark, ${ }^{3}$ Department of Land Resources and Environmental Sciences, Montana State University, Bozeman, Montana 59717, USA, ${ }^{4}$ Geography Department, Humboldt-Universität zu Berlin, 10099 Berlin, Germany, ${ }^{5}$ Max Planck Institute for Meteorology, 20146 Hamburg, Germany, ${ }^{6}$ Centre d'Etudes Spatiales de la BIOsphère (CESBIO), Université Toulouse III, 18 avenue Edouard Belin bpi 2801,31401 Toulouse Cedex 9, 4, France, ${ }^{7}$ Johann Heinrich von Thünen Institute, Institute of Agricultural Climate Research, 38116 Braunschweig, Germany, ${ }^{8}$ Institute of Social Ecology Vienna (SEC) Alpen-Adria University Klagenfurt-Vienna-Graz, 1070 Vienna, Austria, ${ }^{9}$ Department of Biology, Research Group on Plant and Vegetation Ecology, Universiteitsplein 1, 2610 Wilrijk, Belgium, ${ }^{10}$ Department of Meteorology, Institute of Hydrology and Meteorology, Technische Universität Dresden, 01737 Tharandt, Germany, ${ }^{11}$ Woods Hole Research Center, Falmouth, Massachusetts 02540, USA, ${ }^{12}$ INRA, Grassland Ecosystem Research (UREP), 63100 Clermont-Ferrand, France, ${ }^{13}$ Georg-August University of Göttingen, Büsgenweg 2, 37077 Göttingen, Germany, ${ }^{14}$ School of Forestry, Northern Arizona University, Flagstaff, Arizona 86011, USA, ${ }^{15}$ Germany and Earth System Analysis, Potsdam Institute for Climate Impact Research, 14473 Potsdam, Germany, ${ }^{16}$ Finnish Meteorological Institute, Climate Change Research, PO Box 503, FI-00101 Helsinki, Finland, ${ }^{17}$ INRA, unité EPHYSE, 33140 Villenave d'Ornon, France, ${ }^{18}$ F.R.S.-FNRS and Georges Lemaître Center for Earth and Climate, Earth and Life Institute, Universite catholique de Louvain, 1348 Louvain-la-Neuve, Belgium, ${ }^{19}$ Alterra, PO Box 47, 6700 AA Wageningen, The Netherlands, ${ }^{20}$ USDA Forest Service - Southern Research Station, Coweeta Hydrologic Laboratory, Otto, North Carolina 28763, USA, ${ }^{21}$ Center for Ecosystems and Environmental Sustainability, Technical University of Denmark, Department of Chemical and Biochemical Engineering, DTU Risø Campus PO Box 49, 4000 Roskilde, Denmark, ${ }^{22}$ CESAM and Department of Environment, University of Aveiro, Campus de Santiago, 3810-193 Aveiro, Portugal, ${ }^{23}$ CEFE CNRS, 34293 Montpellier Cedex 5, France, ${ }^{24}$ Department Hydrosystemmodellierung, Helmholtz-Zentrum für Umweltforschung GmbH - UFZ, 04318 Leipzig, Germany, ${ }^{25}$ School of Natural Resources, 32 L.W. Chase Hall, PO Box 830728, University of Nebraska-Lincoln, Lincoln, Nebraska 68583 0728, USA, ${ }^{26}$ A.N. Severtsov Institute of Ecology and Evolution, Russian Academy of Sciences Leninsky pr., 33, Moscow, 119071, Russia, ${ }^{27}$ Helmholtz Centre Potsdam, section 5.4 Hydrology, GFZ German Research Center For Geosciences, 14473 Potsdam, Germany, ${ }^{28}$ Department of Earth Sciences, Earth and Climate cluster, VU University Amsterdam, Boelelaan 1085, 1081 HV Amsterdam, The Netherlands. *e-mail: Sebastiaan.Luyssaert@lsce.ipsl.fr 